this experiment, the findings allow two conclusions to be drawn. First, on an ambiguous ability task, strangers responding similarly are seen as both more attractive and more intelligent by a person than strangers responding unlike him. These effects suggest that, at least when similarity of ability enhances the person's apparent competence, similarly able others are liked more than dissimilar others. Second, one source of variance in interpersonal judgments of similarly and dissimilarly responding others is the person's habitual anxiety about the quality of his own performance on tests. With increasing test anxiety, people make more tentative ratings of the stranger.

An alternate interpretation of the similarity effect is possible. Assuming they knew they had done well, the most capable Ss may have liked the similar stranger merely because he did well rather than because he was similar, as such. Likewise, they may have disliked the dissimilar stranger merely because he did poorly. However, correlations between attraction ratings and vocabulary test scores show that Ss doing well on the test were no more prone than others to like similar $(r=.07)$ or dislike dissimilar strangers $(r=-.18)$. These low correlations indicate that the similarity effect was not dependent on how well $\mathrm{S}$ did.

An ability interpretation is also possible for the anxiety effect. The vocabulary test was constructed to eliminate objective cues to correctness, so the only clue to the quality of the stranger's performance was his agreement with the S's own responses. Since test-anxious Ss have a low opinion of their own ability, it follows that similar others would appear incompetent and dissimilar others would appear more competent. Indeed, when intelligence ratings were analyzed, a significant interaction between anxiety and intelligence established just this pattern. However, the correlations between anxiety and intelligence (similarity, -.16; dissimilarity, .39) are no greater than those between anxiety and the other judgment items (knowledge of current events, -.27 , .39 ; independent thinking $-.23, .22$; conversational ability, $-.36, .36$; and attraction, $-.29, .37)$. Also, the correlation of attraction with intelligence is of the same order as the correlations between attraction and the other items, indicating that perceived ability or intelligence did not play a special role in determining attraction. Since all of the Judgment Scale items showed the same restrictive effects of anxiety, it appears that test-anxious Ss place less confidence in their ability to make any accurate judgments about another person, especially when their own fallible responses serve as the standard.

\section{REFERENCES}

BYRNE, D. Interpersonal attraction and attitude similarity. Journal of Abnormal \& Social Psychology, 1961, 62, 713-715.

CLORE, G. L., \& BYRNE, D. The process of personality interaction. In R. B. Cattell (Ed.), Handbook of modern personality theory. Vol. 2. Chicago: Aldine, in press.

FESTINGER, L. A theory of social comparison processes. Human Relations, 1954, 7, 117-140.

MANDLER, G., \& SARASON, S. A study of anxiety and learning. Journal of Abnormal \& Social Psychology, 1952, 47, 166-173.
SARASON, I. G. I:mpirical findings and theoretical probicms in the use of anxicty scales. Psychological Bulletin. 1960, 57. 403-415.

ZANDER, A., \& HAVELIN, A. Social comparison and interpersonal attraction. Human Relations. 1960, 13, 21-32. NOTE

1. The data were reported in an MA thesis by Pamela Reagor. Rosemaric Abendroth, David Doty, Jenifer Hokman Doty, Karl Joneitz. David Schickendanz, and Barbara Stacy helped conduct the experiment. This report was supported by Research Grant MH-14510 from the National Institute of Mental Healt), United States Public Health Service.

\title{
Individual differences in subjective organization: short-term memory ${ }^{1}$
}

\author{
MARCIA EARHARD, Dalhousie \\ University, Halifax, N.S., Canada
}

An experiment was conducted to determine whether the individual differences in subjective organization that appear during free-recall memorization are due to individual differences in short-term memory or to individual differences in the ability to form and maintain interitem associations as had been suggested by Earhard (1967) and Earhard \& Endicott (1969). Ss preselected as high and low subjective organizers, according to their performance during free recall, were tested for short-term memory by the task introduced by Peterson \& Peterson (1959). The results indicated that high and low subjective organizers do not differ in short-term memory. These results were discussed in terms of the dichotomy between short-term and long-term memory processes.

Earhard (1967) and Earhard \& Endicott (1969) have reported the results of two pairs of experiments designed to determine the processes that allow individuals who 
organize well during free recall (FR) to remember better. The measure of organization during free recall was the Subjective Organization (SO) score (Tulving, 1962), which reflects the consistency with which items are recalled in the same sequence from one FR trial to the next. There is sufficient evidence now that SO and FR performance are functionally related (e.g., Mayhew, 1967) and that other measures of organization during FR are correlated with SO (Puff \& Hyson, 1967). The Earhard experiments showed that Ss who are classified as high subjective organizers (HSO) according to their FR behavior patterns perform better than do Ss who are classified as low subjective organizers (LSO), under a variety of other task conditions, specifically, serial recall (Earhard, 1967), and paired-associate learning (Earhard \& Endicott, 1969). These findings were interpreted as giving strong support to the notion that the advantage of the HSO learner during memorization is his superior ability to form and retain interitem associations.

There are, of course, alternate hypotheses to account for the findings cited above, and it is to provide evidence concerning one of these that the experiment below is reported here. It is possible that the differences between high and low subjective organizers originate in individual differences in the ability to retain each item in the stimulus array, regardless of the associative memory structure imposed on those items by the learners and reflected in their SO scores. If this were the case, then one should be able to demonstrate that LSO learners are less able to retain single items over short periods of time and short interpolations of interfering activities. To determine if high and low subjective organizers differ in this type of short-term memory (STM), the experiment below tested HSO and LSO Ss under the typical Peterson \& Peterson (1959) STM test conditions.

\section{PRELIMINARY PROCEDURE}

To obtain a sample of high and low subjective organizers, a large group of undergraduate students enrolled in an introductory course in psychology at St. Mary's University participated in a group free-recall experiment, in which the procedure of Earhard (1967) was followed. These students were given 16 practice trials in a typical FR group experiment, in which they memorized a list of 22 unrelated English words. Subjective organization scores based on the 16 recall protocols of each $S$ were then calculated according to the method outlined by Tulving (1962). The Ss who obtained the lowest 15 SO scores (mean $\mathrm{SO}=.25$ ) were arbitrarily designated as LSO; the 15 highest scorers (mean SO $=.41$ ) became the HSO group. TESTING PROCEDURE

The method followed the description of Peterson \& Peterson (1959), with some minor differences. Fifteen HSO Ss and 15 LSO Ss were presented, by memory drum, with 48 Witmer consonant syllables (Hilgard, 1951), each of which was followed by a three-digit number from which the Ss were required to count backwards by threes, until a buzzer sounded, at which point the Ss were required to recall the consonant syllable that had preceded the most recent number. There were three orders of presentation of the syllables and several different starting positions. Six intervals of delay between the presentation of the syllable and the sounding of the buzzer were used eight times each throughout a session. The intervals were $0,3,6,9,12$, and $18 \mathrm{sec}$. The six intervals were assigned sandomly to syllables in the three different orders, with the restriction that each interval be tested equally often before any one be tested again.

Before the experimental session began, the Ss were instructed about their task and given two practice syllables to familiarize them with the procedure to be followed.

\section{RESULTS}

The above design yielded $15 \times 8$ responses at each delay interval. The results are presented in Fig. 1 where it is obvious that short-term memory did not vary as a function of subjective organization. The drop in number of correct responses as a function of delay is typical of this type of experiment. Analysis of variance confirmed that there was an effect of delay length

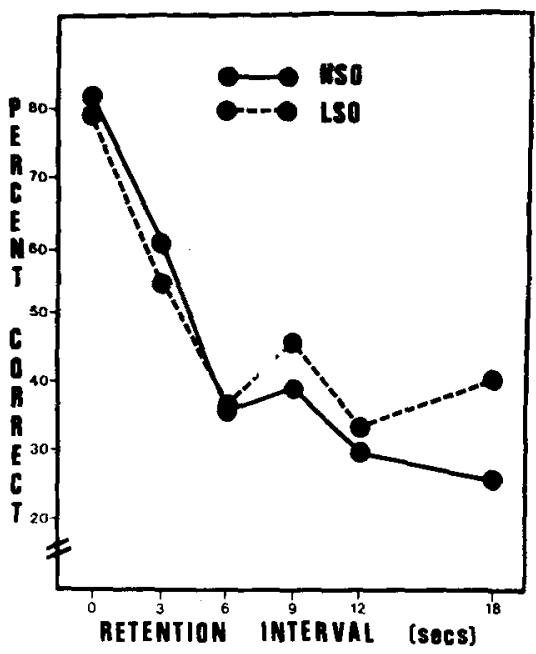

Fig. 1. Short-term retention of high and low subjective organizers as a function of length of interpolated activity.
$[F(5,140)=40.8, p<.01]$ but not of SO $[F(1,28)<1]$.

\section{DISCUSSION}

The results of this experiment deny the hypothesis that the superiority of HSO learners during free recall and a variety of other memory-task situations is accountable entirely in terms of the STM factor. The most reasonable interpretation of the Earhard and the Earhard and Endicott findings remains, it seems, some $k$ ind of individual-difference variable related to the ability to form and maintain interitem associations.

The present results may have implications for the question of whether or not short-term and long-term memory involve different processes (cf. Melton, 1963). Whatever a high subjective organizer does during free recall to improve the number of words he recalls correctly, that activity does not seem to operate during a task where only STM is involved, even though other research has shown that high and low organizers do differ in tasks other than free recall, e.g., serial recall and paired-associate learning. The suggestion here seems to be that at least one of the processes that are common to the tasks that have been considered tests of long-term memory does not appear to operate during an STM task under the conditions described here.

\section{REFERENCES}

EARHARD, M. Subjective organization and list organization as determinants of free-recall and serial-recall memorization. Journal of Verbal Learning \& Verbal Behavior, 1967, 6, 501-507.

EARHARD, M., \& ENDICOTT, 0 . Why are there individual differences in subjective sequential organization during free-recall memorization? Journal of Verbal Learning \& Verbal Behavior. $1969,8,316-319$.

HILGARD, E. R. Methods and procedures in the study of learning. In S. S. Stevens (Ed.), Handbook of experimental psychology. New York: Wiley, 1951.

MAYHEW, A. J. Interlist changes in subjective organization during free-recall learning. Journal of Experimental Psychology, 1967, 74, 425-430.

MELTON, A. W. Implications of short-term memory for a general theory of memory. Journal of Verbal Learning \& Verbal Behavior, $1963,2,1-21$.

PETERSON, L. R., \& PETERSON, M. J. Short-term retention of individual verbal items. Journal of Experimental Psychology, 1959, 58, 193-198.

PUFF, C. R., \& HYSON, S. P. An empirical comparison of two measures of intertrial organization in free recall. Psychonomic Science, $1967,9,329-330$.

TULVING, E. Subjective organization in free recall of "unrelated" words. Psychological Review, 1962, 69, 344-354.

\section{NOTE}

1. This research was supported by Grant APA-214 from the National Research Council of Canada. The cooperation of Dr. J. Gordon of St. Mary's University is gratefully acknowledged. Sandra Brown conducted the experiment. 